$2018,19(4)$, pp. 948 - 962, DOI : 10.18038/aubtda.425027

\title{
ASSESSMENT OF RADIO SPECTRUM PROFILE IN NIGERIA USING MULTI-BAND AND MULTI-LOCATION RADIO SPECTRUM OCCUPANCY MEASUREMENTS
}

\author{
Jide Julius POPOOLA ${ }^{1, *}$, Uche Nwafor OTUU ${ }^{2}$ \\ ${ }^{1}$ Department of Electrical and Electronics Engineering, School of Engineering and Engineering Technology, Federal \\ University of Technology, Akure, Nigeria. \\ 2 Department of Electrical and Electronics Engineering, School of Engineering and Engineering Technology, Federal \\ University of Technology, Akure, Nigeria .
}

\begin{abstract}
This paper presents multi-band and multi-location spectrum measurements campaign conducted in Nigeria in $80-2200 \mathrm{MHz}$ frequency range. The objectives of the study are to quantitatively determine the actual radio spectrum usage profile situation in Nigeria and to determine the radio spectrum usage profile in Nigeria in time, frequency and space. The results from the spectrum measurements campaign show that a lot of allocated frequency bands in Nigeria have very low signal occupancy rates with the occupancy rates vary randomly in time, frequency and space like other parts of the world. The spectrum measurements campaign results also show that the actual spectral occupancy in Nigeria is less than $10.00 \%$. The low spectral occupancy rate in the five major metropolises suggests a hopeful future for dynamic spectrum access in Nigeria.
\end{abstract}

Keywords: Radio spectrum, Spectrum occupancy measurement, Radio spectrum monitoring, Spectrum sensing methods, Duty cycle

\section{INTRODUCTION}

The radio spectrum is a precious and renewable natural resource that supports wireless communication systems. Despite its renewable nature, the radio spectrum has recently being considered as a scarce resource as a result of the way it is being managed. This necessitates the need for effective management of this precious resource to ensure its efficient and equitable access for the services which use it. Historically, the radio spectrum has been regulated worldwide by government agencies at both the international and national levels. While at the international level, spectrum is being apportioned by International Telecommunication Union into blocks for specific uses, at the national level, licenses are assigned for these blocks to specific users. This divide and set aside policy also known as fixed radio spectrum allocation policy grants exclusively right to use the assigned spectrum to licensed users on a long-term basis. The mission of this traditional radio spectrum regulatory policy is to ensure interference-free operations of wireless systems, which indeed protect harmful interference in allocated bands.

However, as demand for and use of radio spectrum is increasing with daily advent of new wireless devices and applications that required radio spectrum, observations have shown clearly that traditional fixed radio spectrum allocation policy is no more effective and efficient in radio spectrum management. For instance, results from several radio spectrum occupancy measurements conducted in different parts of the world have shown that most of the allocated frequency bands under the current fixed radio spectrum allocation policy are not in use most of the time [1-6]. Similarly, as reported in [7], the policy has been identified as the main causes of both spectrum scarcity and spectrum underutilization currently experiencing worldwide. According to [7], these problems of spectrum scarcity and spectrum underutilization caused by the current fixed spectrum allocation policy have also been observed by some radio spectrum regulatory bodies such as Office of Communications

*Corresponding Author: jidejulius2001@gmail.com

Received: 18.05.2018 Accepted: 06.12.2018 
(Ofcom) in the United Kingdom and the Federal Communication Commission (FCC) in the United States. These regulatory bodies' inferences were based on high variability of traffic statistics across time, space and frequency in most of the allocated frequency bands under the current fixed radio spectrum allocation policy. For instance, the radio spectrum occupancy measurements results reported in [8] showed that actual spectrum usage is concentrated over certain licensed bands while a significant amount of the licensed bands are underutilized or unused for $90 \%$ of the time.

These observations lead to the general view of reconsidering current fixed radio spectrum allocation policy with a view of finding a better policy of managing the radio spectrum. However, since it is practically infeasible to manage what has not been measured, this necessitates several radio spectrum occupancy measurement campaigns around the world. The role of radio spectrum occupancy measurement in determining the actual utilization level of licensed spectrum or frequency band cannot be overestimated. This is because its knowledge helps researchers and other relevant radio spectrum policy makers to devise appropriate spectrum model(s) that could be used to predict future radio spectrum utilization [9]. As reported in [9], one of the advantages of radio spectrum occupancy measurements is that it helps radio spectrum policy makers in determining the frequency bands that have low occupancy in order to determine specific bands that are suitable for opportunistic spectrum access (OSA) also known as dynamic spectrum access (DSA). In the actual sense, radio spectrum occupancy measurement is difference from radio spectrum monitoring. While the latter is to provide detailed information on conformity with laid down rules relating to radio spectrum usage, which radio spectrum planners use to ascertain the level of spectrum users' compliance to spectrum usage rules as well as confirming the level of effectiveness of current radio spectrum planning system, the former on the other hand is used to quantify the usage profile of specific measuring band per time.

Actually, several radio spectrum occupancy measurements have been conducted to estimate the actual radio spectrum utilization profiles in various geographical regions or locations around the world. However, it has been observed that out of the several spectrum occupancy measurements conducted around the world, most were done in the United States of America (USA) and Europe with few in Asia and Africa [10]. For instance in Nigeria, some radio spectrum occupancy measurements had been carried out, however, none of them really involved different geo-political zones of the country. Thus, in order to assess the level of radio spectrum usage profile across multiple geo-political zones in Nigeria, the study reported in this paper was embarked upon with a view to determining the behavior of the spectrum utilization patterns in different frequency bands across different geo-political zones of the country. The objectives of the study are not only to fill the gap on current lack of information on multiband and multi-location radio spectrum usage pattern in Nigeria, but also to determine whether or not the radio spectrum utilization patterns in multiband and multi-location in Nigeria vary with time, space and frequency like other parts of the world. Also, to find out availability of frequency bands for DSA as well as to determine whether or not to support other parts of the world in calling for the replacement of the current fixed allocation policy with a more flexible allocation policy. For sequential and logical presentation of the study reported in this paper, the rest of this paper is structured as follows. Section 2 presents review on related work on radio spectrum occupancy measurements around the world. In Section 3, detail on spectrum occupancy measurement conducted in this paper is presented. The section presents the descriptions of study locations, measurement setup and the measurement methodology for the study. The spectrum occupancy measurement results obtained are presented and discussed in Section 4. The paper is finally concluded in Section 5 with summary of our findings and recommendation.

\section{RELATED WORK}

Basically, spectrum occupancy measurement is the primary quantitative tool that provides the radio spectrum regulators, researchers, engineers and policy makers with the necessary information on radio frequency usage pattern by licensed users in different frequency bands. Around the world, several 
researchers, [11-13], have conducted similar radio spectrum occupancy measurements as present in this paper. All these researchers discovered through the actual spectral occupancy measurements they conducted that large portions of the licensed frequency bands are rarely or randomly used by the licensed users while some frequency bands are overcrowded. For example, the results of first radio spectrum occupancy study that was carried out in 1998 by the National Telecommunications and Information Administration (NTIA) in USA showed that spectrum occupancy activity on a band-byband is higher in coastal cities than in Midwestern cities [11]. Similarly, another large scale spectrum occupancy measurement result conducted in Chicago, USA by [14] shows that $82.6 \%$ of the licensed spectrum considered was unoccupied during the spectrum occupancy measurement.

Similarly, radio spectrum occupancy measurement conducted in 180-2700 MHz band in the urban area of Hull City, United Kingdom by [3] demonstrated that a significant amount of unused spectrum in these bands with an overall mean occupancy ratio as low as $11.04 \%$ over the whole band. Also, in another radio spectrum utilization measurements that were conducted in Europe in the suburb of the city of Brno in the Czech Republic and in the suburb of Paris in France and the city of Paris in France in $400 \mathrm{MHz}-3 \mathrm{GHz}$ band by [15] show variations in radio spectrum usage in the three regions with overall spectrum utilization of $6.5 \%, 10.7 \%$ and $7.7 \%$ respectively. Likewise, in a broadband spectrum measurement campaign conducted in Europe, by [16] in frequency range from $75 \mathrm{MHz}$ to $7 \mathrm{GHz}$ in both indoor and outdoor scenarios in urban and suburban locations in Barcelona, Spain revealed the existence of a significant amount of unused spectrum, which can be opportunistically used by secondary users.

Similar studies on actual spectrum occupancy measurements in Asia revealed similar results like other parts of the world. For instance, the multidimensional spectrum occupancy measurement campaign conducted in Qatar to study the evolution of radio frequency over time, frequency, and space considering the spectrum between $700-3000 \mathrm{MHz}$ by [17] at four different locations showed spatial variation in spectrum utilization per day with actual utilization varies between $4 \%$ and $15 \%$. Similarly, the result of the spectrum occupancy measurement conducted in Malaysia, another country in Asia by [18] to investigate spectrum occupancy on cellular and television (TV) bands indicated varying average duty cycle of 35\%, 10\% and 26\% for GSM900, GSM1800 and 3G cellular networks respectively while the corresponding values for the very high frequency (VHF) and ultra high frequency (UHF) of the TV broadcasting bands are $11 \%$ and $13 \%$ respectively. The results of these studies indicated that utilization of most of the allocated frequency bands in Malaysia are below 15\%.

Similarly, in Africa, some studies on radio spectrum occupancy measurements were conducted in countries like South Africa, Uganda and Nigeria to mention but a few. For instance in South Africa, the spectrum occupancy measurements carried out by [19] in the Hatfield area of Pretoria for UHF band, GSM $900 \mathrm{MHz}$ and GSM $1800 \mathrm{MHz}$ bands indicated variations in usage of the three bands with the UHF band has an occupancy of about $20 \%$ while those of GSM $900 \mathrm{MHz}$ and GSM $1800 \mathrm{MHz}$ bands are about $92 \%$ and $40 \%$ respectively. Similar study carried out in Kampala, the Uganda capital presented in [20] using GSM900, GSM1800, the universal mobile telecommunications system 2100 (UMTS2100) and long term evolution 2600 (LTE2600) bands show variations in those frequency bands considered. The result of the study indicated an average occupancy rate of $8.8 \%$ and $52.4 \%$ respectively for both the uplink and downlink in GSM900 band while the corresponding values obtained for the uplink and downlink occupancy rate for GSM1800 band are $0.6 \%$ and $13.6 \%$ respectively. On the other hand, the obtained uplink and downlink occupancy results in the study for the UMTS 2100 band are $0.56 \%$ and $48.7 \%$ respectively while the corresponding results for the LTE2600 band are $0 \%$ and $0.6 \%$ respectively.

Similarly, in Nigeria, one of the studies on spectrum occupancy measurements conducted at Gwarinpa District in Abuja, the Nigeria Federal Capital Territory (FCT) shows that there is variations in usage of licensed spectrum in Abuja; with utilization level ranges from $17 \%$ to $26 \%$ at $700-2400 \mathrm{MHz}$ 
frequency bands. Similarly, recent study conducted in South-West Geo-political zone of Nigeria by [10] revealed that the actual radio spectrum usages in the zone for the frequency range of 80-2200 $\mathrm{MHz}$ vary from $0.08 \%$ to $64.4 \%$.

These results generally show gross underutilization of licensed spectrum in Africa as in other parts of the world as well as a common finding that a large portion of the licensed spectrum are rarely or sporadically used while some particular spectrum bands are overcrowded. Also, the results indicated that large amount of the spectrum resources is poorly utilized with low spectrum usage efficiency. However, the agreement of the results of spectrum occupancy in Africa and Nigeria in particular does not negate the necessitate of this study since the objectives of the study as stated above are not only to fill the gap on current lack of information on multiband and multi-location radio spectrum usage pattern in Nigeria, but also to determine whether or not the radio spectrum utilization patterns in multiband and multi-location in Nigeria vary with time, space and frequency like other parts of the world. Also, to find out availability of frequency bands for DSA as well as to determine whether or not to support other parts of the world in calling for the replacement of the current fixed allocation policy with a more flexible allocation policy. Thus, the primary contribution of this paper is to quantify spectrum utilization in the frequency bands considered in order to explore the possibility of employing cognitive radio or other wireless communication systems in the bands in the nearest future. The stepby-step activities involved in achieving this study's objectives and main contribution are presented in the next section.

\section{MEASUREMENT DESCRIPTIONS}

Traditionally, according to [21], there are some factors, that need to be considered when setting a strategy to meet a particular radio spectrum occupancy measurement. These factors as reported by [2] are: (i) time (sampling rate and measurement period), (ii) frequency (frequency span or band and frequency points to be measured within the selected frequency span or band), (iii) location (measurement site selection), (iv) direction (use of omni-directional or directive antenna; and the antenna pointing angle in the case of directive antenna) and (v) polarization (receiving antenna polarization). According to the authors in [2], the configuration of the parameters for each of the factors determines the ways the spectrum occupancy patterns are observed and also plays important roles in both the accuracy and reliability of obtained spectrum occupancy results or data. Thus, in providing detailed information on the factors, this section is divided into three stages: measurement geographical locations, measurement setup and measurement methodology. Detailed information on each factor as well as activities involved in each stage is presented in the following subsections.

\subsection{Measurement Geographical Locations}

This spectrum measurement campaigns were conducted in five locations in Nigeria. The choice of the locations was based on the fact that similar study, except in Abuja, the nation Federal Capital Territory (FCT), has not been carried out in such locations. The five locations cut across three geo-political zones in the country. The studies' locations are Abuja, Lafia, Lokoja, Gusau and Port-Harcourt. The respective states, marked 1-5, on the map of Nigeria shown in Figure 1 show where the studies were conducted while detailed information on each of the exact locations where the measurements were actually conducted is presented in Table 1 . 


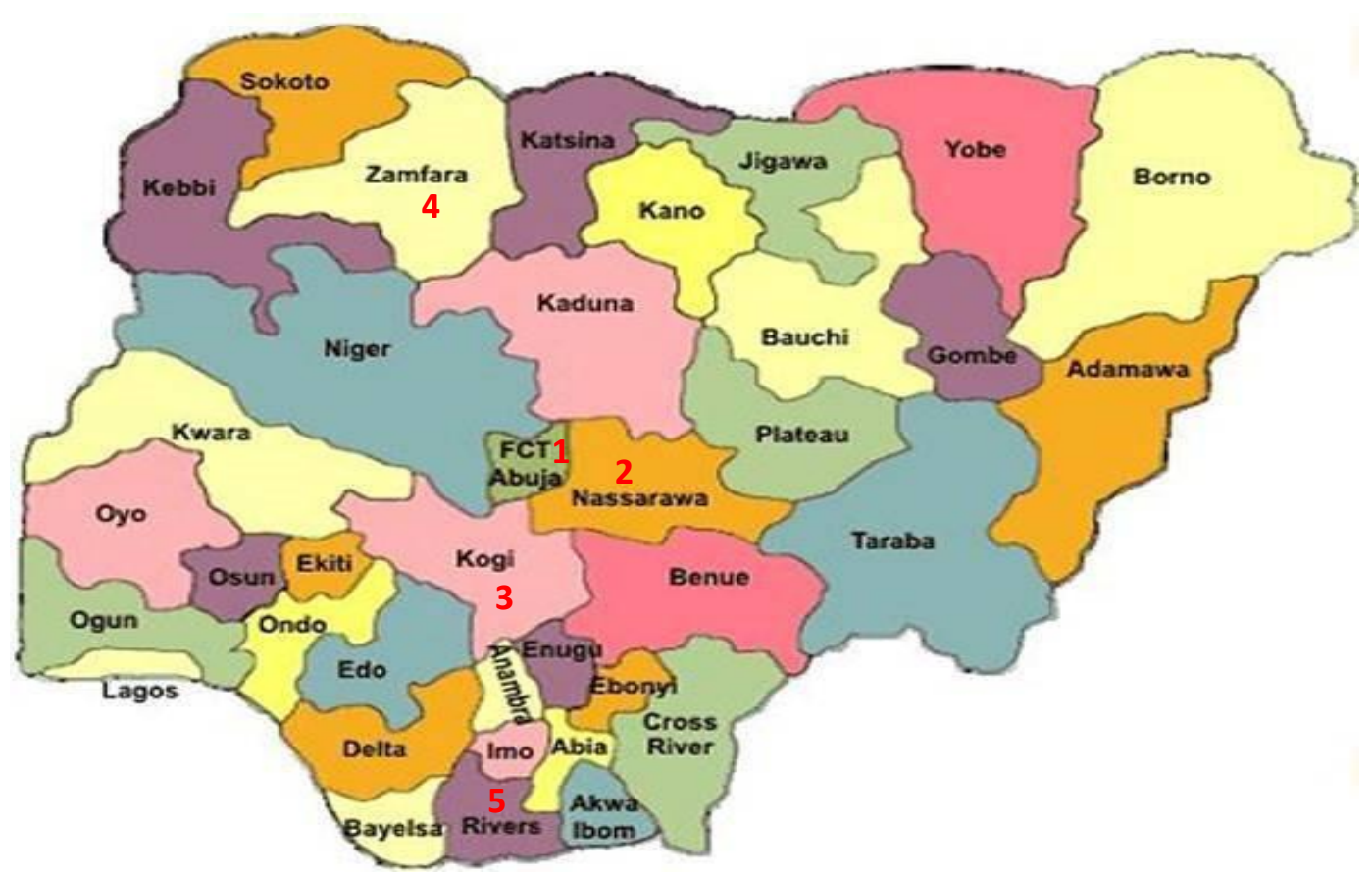

Figure 1. Nigeria map showing respective states where measurements were conducted

Table 1. Measurement sites details

\begin{tabular}{|c|c|c|c|c|}
\hline Study City & State & $\begin{array}{c}\text { Geo-political } \\
\text { Zone }\end{array}$ & Study Site & Site Coordinates \\
\hline Abuja & FCT & North-Central & $\begin{array}{c}\text { COREN } \\
\text { Headquarter } \\
\text { Wuse Zone } 4\end{array}$ & $\begin{array}{c}\text { Latitude: } 9^{0} 4^{\prime} 0^{\prime \prime} N \\
\text { Longitude: } 7^{0} 28^{\prime} 60^{\prime \prime} E\end{array}$ \\
\hline Lafia & Nasarawa & North-Central & $\begin{array}{l}\text { Nsuk, Along } \\
\text { Keffi Akwanga } \\
\text { Road }\end{array}$ & $\begin{array}{c}\text { Latitude: } 6^{0} 31^{\prime} 0^{\prime \prime} N \\
\text { Longitude: } 3^{0} 21^{\prime} 0^{\prime \prime} E\end{array}$ \\
\hline Lokoja & Kogi & North-Central & Diato Hotel & $\begin{array}{c}\text { Latitude: } 7^{0} 48^{\prime} 14^{\prime \prime} N \\
\text { Longitude: } 6^{0} 44^{\prime} 58^{\prime \prime} E\end{array}$ \\
\hline Gusau & Zamfara & North-West & $\begin{array}{c}\text { Samaru Gida } \\
\text { Kofa }\end{array}$ & $\begin{array}{c}\text { Latitude: } 12^{0} 9^{\prime} 76^{\prime \prime} N \\
\text { Longitude: } 6^{0} 39^{\prime} 68^{\prime \prime} E\end{array}$ \\
\hline $\begin{array}{l}\text { Port- } \\
\text { Harcourt }\end{array}$ & Rivers & South-South & $\begin{array}{l}\text { LFC, Port- } \\
\text { Harcourt D-Line }\end{array}$ & $\begin{array}{c}\text { Latitude: } 4^{0} 47^{\prime} 21^{\prime \prime} N \\
\text { Longitude: } 6^{0} 59^{\prime} 54^{\prime \prime} E\end{array}$ \\
\hline
\end{tabular}

In this study, two categories of measurement campaigns are reported. The first category was conducted indoor in rooms located in modern buildings while the second category was performed outdoor on roofs of high-rise story buildings such that most of the buildings around are below the 
measurement points. Also, the choice of measurement points was such that no other building blocked the targeted radio signal considerably.

\subsection{Measurement Setup}

The measurement setup employed, as shown in Figure 2, is the same for all the locations. The photo of the setup as shown in Figure 2 consists of an Aaronia AG HF-6065 V4 spectrum analyzer, an Aaronia omni-directional AG HyperLOG 7060 antenna, a laptop and an MCS software specially designed to run on Aaronia AG spectrum analyzers. The measurement setup relies on the spectrum analyzer, which other devices were connected to in order to improve the setup detection capability and the overall accuracy and reliability of obtained data. The main parameters of the Aaronia AG HF-6065 V4 spectrum analyzer used are presented in Table 2. The connected omni-directional antenna to the spectrum analyzer is a broadband antenna with wide frequency range and in-built filters to remove out-of-band signals and undesired overloading. Another in-built component of the antenna is a lownoise preamplifier that enhances the general sensitivity and the detection capability of the spectrum analyzer in detecting weak signals.

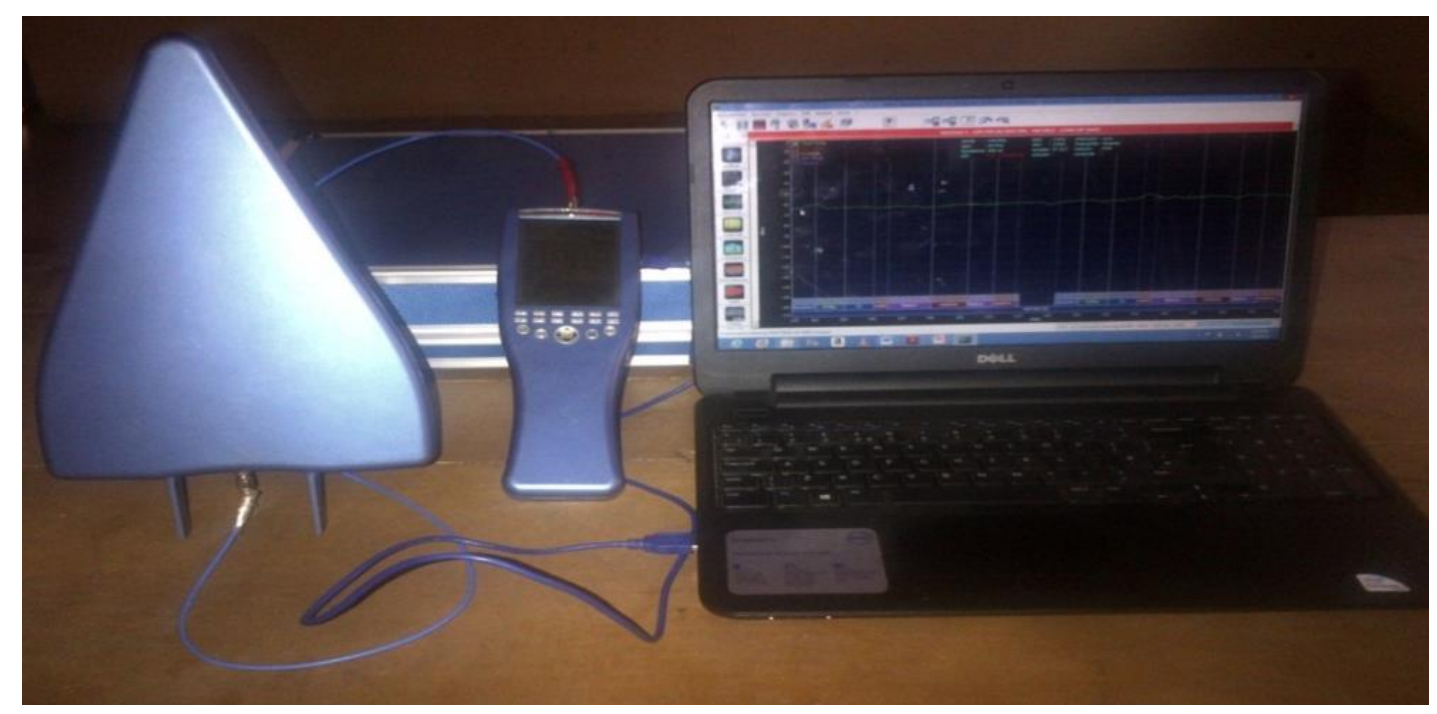

Figure 2. Measurement setup

Table 2. Parameters of used spectrum analyzer

\begin{tabular}{cc}
\hline Parameter & Value \\
\hline Radio frequency (RF) range & $10 \mathrm{MHz}-6 \mathrm{GHZ}$ \\
Display Average Noise Level & $-135 \mathrm{dBm}$ \\
(DANL) & $-150 \mathrm{dBm}$ \\
DANL with Preamp & $+10 \mathrm{dBm}$ \\
Maximum Power at RF Input & $10 \mathrm{~ms}$ \\
Lowest Sample Time & $3 \mathrm{kHz}-50 \mathrm{MHz}$ \\
Resolution Bandwidth (RBW) & Input \\
Interface & USB 2.0/1.1 \\
\hline
\end{tabular}


The antenna thus enhances high performance of the spectrum analyzer in recording the spectral activity. The other connected device to the spectrum analyzer is a laptop system. The laptop, which was connected to the spectrum analyzer via a USB cable, serves two purposes. The first is to store the spectral activities recorded by the analyzer while its second responsibility is to serve as the display unit for the setup. The block diagram representation of the measurement setup is shown in Figure 3. The arrows in Figure 3 show the direction of flow of signal in the setup. As shown in Figure 3, while the antenna receives the signal, the spectrum analyzer will quantify its value, which will be displayed and stored in the laptop.

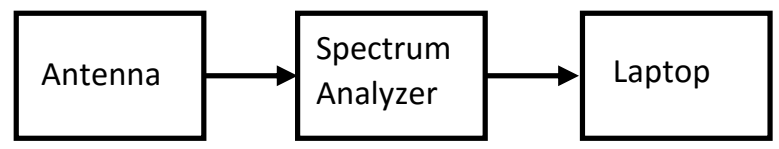

Figure 3. Block diagram representation for the measurement setup

\subsection{Measurement Methodology}

The methodological procedures employed in this study are in line with the fundamental procedures provided by [21]. The spectrum measurement surveys were conducted during weekday for 24 hours in each location over a 3 week time span at the five locations from November 25, 2016 to December 13, 2016. The measurement surveys covered the frequencies from $80 \mathrm{MHz}$ to $2200 \mathrm{MHz}$. The considered frequency range was further sub-divided into 8 sub-measurement bands. In determining the actual spectrum occupancy or utilization of the services bands, the presence of the licensed or primary users' signals in those frequencies bands were sensed using a spectrum sensing method.

In determining primary user signal, there are various spectrum sensing methods or techniques proposed in literature. Some of these spectrum sensing methods are matched filter detection [22], cyclostationary feature detection [23], automatic modulation classification detection [24], and energy detection [25-26] to mention but a few. Among these spectrum detection methods, energy detection is the most acclaimed method [24], because it is the only method that measures only the power of the received signal in determining the presence of the licensed users' signals in a given frequency band. Thus, in this study, the energy detection method was adopted to determine the power spectral density (PSD) of each licensed band signals in the considered frequency bands. Basically, in energy detection method employed, the received signal power for each frequency band is to be compared to a predefined threshold value. Thus, the threshold value for each frequency band at each location was determined because when energy detection method is employed in radio spectrum occupancy measurements, correct determination of the decision threshold upon which a particular channel can be either deemed busy or free is essential since there is no prior-knowledge about the channel.

In determining the decision threshold value for each frequency band at each location for this study, the average noise level was first determined by connecting a $50 \Omega$ resistor to the spectrum analyzer used. The decision threshold was set by adding $3 \mathrm{~dB}$ to measured thermal noise. Although the decision threshold recommended by International Telecommunication Union (ITU) spectrum monitoring handbook is $10 \mathrm{~dB}$ above the average noise floor, $3 \mathrm{~dB}$ was employed because addition of high value above 3 to $6 \mathrm{~dB}$ to the noise floor had adverse effect on the accuracy of the occupancy measurement. The decision threshold obtained varies from one location to another as well as the frequency band since the noise level varies with locations and frequencies. The decision threshold value for respective frequency band in each location is indicated with parallel line on Figure 4. The average measured occupancy or duty cycle, which is defined according to [19] as the fraction of time the signal is present, is computed using the mathematical expression given in $[1,3]$ as: 


$$
\text { Duty Cycle }=\frac{\text { Signal occupation period }(n)}{\text { Total observation period }(m)} \times 100 \%
$$

On the other hand, when a time series of the channel power measurements is employed, the duty cycle is computed using the expression;

$$
\text { Duty Cycle }=\frac{n t}{m} \times 100 \%
$$

where $\mathrm{n}$ is the number of time slots $\mathrm{t}$, where the received signal level is above the decision threshold and $\mathrm{m}$ is the total number of time slots. For this study, the measurement configuration parameters for the spectrum survey are presented in Table 3. The measured frequency bands were divided into eight continuous sub-bands as shown in Table 3. In each of the sub-bands, over 10000 traces were obtained, which were saved and processed offline using MATLAB software tool. The results obtained are presented and discussed in the next section.

Table 3. The measured sub-bands details

\begin{tabular}{cc}
\hline Parameter & Value \\
\hline & Sub-band 1: Radio $(80-150 \mathrm{MHz})$ \\
& Sub-band 2: TV and Land Mobile $(150-400 \mathrm{MHz})$ \\
Sub-band 3: TV $(400-960 \mathrm{MHz})$ \\
Frequency band & Sub-band 4: Trunk Radio Services and GSM $(700-1000 \mathrm{MHz})$ \\
& Sub-band 5: GSM $(900-1300 \mathrm{MHz})$ \\
& Sub-band 6: Rural Telecoms and GSM $(1300-1700 \mathrm{MHz})$ \\
Timing & Sub-band 7: GSM, Oil coy and Satellite Broadcast $(1700-1900 \mathrm{MHz})$ \\
Sandwidth Filter & $500 \mathrm{~ms}$ \\
Video Filter & $200 \mathrm{MHz}$ \\
& $200 \mathrm{MHz}$ \\
\hline
\end{tabular}

\section{RESULTS AND DISCUSSION}

This section presents the measurement results, analyses and discussions. The section is divided into three sub-sections. In the first sub-section, the results of the spectrum utilization analysis based on continuous measurements are presented. Some typical graphical representations of the results in some frequency bands and locations were presented due to space. In the second sub-section, the numerical results of the actual spectrum occupancy in each respective location and frequency band are presented. In the third sub-section, the average duty cycle result for this study was compared with results from similar studies in Nigeria and other parts of the world in order to validate the obtained result in this study. Details on each sub-section are presented in the following sub-sections.

\subsection{Continuous Measurement Results}

Figures 4(a)-(e) show the typical graphical representation of the actual spectrum usage profile for five locations per time. Only this sub-band is presented because of space. The figures show clearly the variations in power spectral density (PSD) against frequency in the monitored frequency band. With the threshold values of approximately $-75 \mathrm{dBm}$, the figures show energy variation in each location in time, frequency and space in the frequency band. This implies variations in radio spectrum usage in time, frequency and space. Though the measurements for the locations were taken over the same hours, they were not taken simultaneously. The variations observed in Figures 4(a)-(e) show clearly 
that actual radio spectrum usage vary with time. Also, Figures 4(a)-(e) show that while certain frequency ranges were heavily utilized, some were sparsely utilized while some were medially utilized. For instance, in Figures 4(a)-(e), it is shown that while 900-1000 MHz are heavily utilized in all the five locations, $1000-1150 \mathrm{MHz}$ were medially utilized and 1150-1300 MHz were sparsely utilized. Similarly, the figures show variations in power amplitude, which implies variations in spectrum usage in each location. These overall results show that spectrum usage vary in time, frequency and space in the studied locations, which is in agreement with the measurement results obtained by other investigators $[16,17,26,27]$.

Furthermore, the overall results from Figures 4(a)-(e) also indicate that the Global System for Mobile Communication-900 (GSM-900), which its uplink and down link frequency band for the four major GSM operators in Nigeria is from $890-960 \mathrm{MHz}$ according to [28] is heavily utilized in all the study locations. This result has therefore qualitatively shown clearly that there is availability of both spatial and temporal spectrum gaps not occupied by licensed or primary users in Nigeria radio spectrum like other parts of the world. The obtained results thus encourage the deployment of cognitive radio technology so as to optimize radio spectrum utilization profile in Nigeria. 
Popoola and Otuu / Eskişehir Technical Univ. J. of Sci. and Tech. A-Appl. Sci. and Eng. 19 (4)-2018
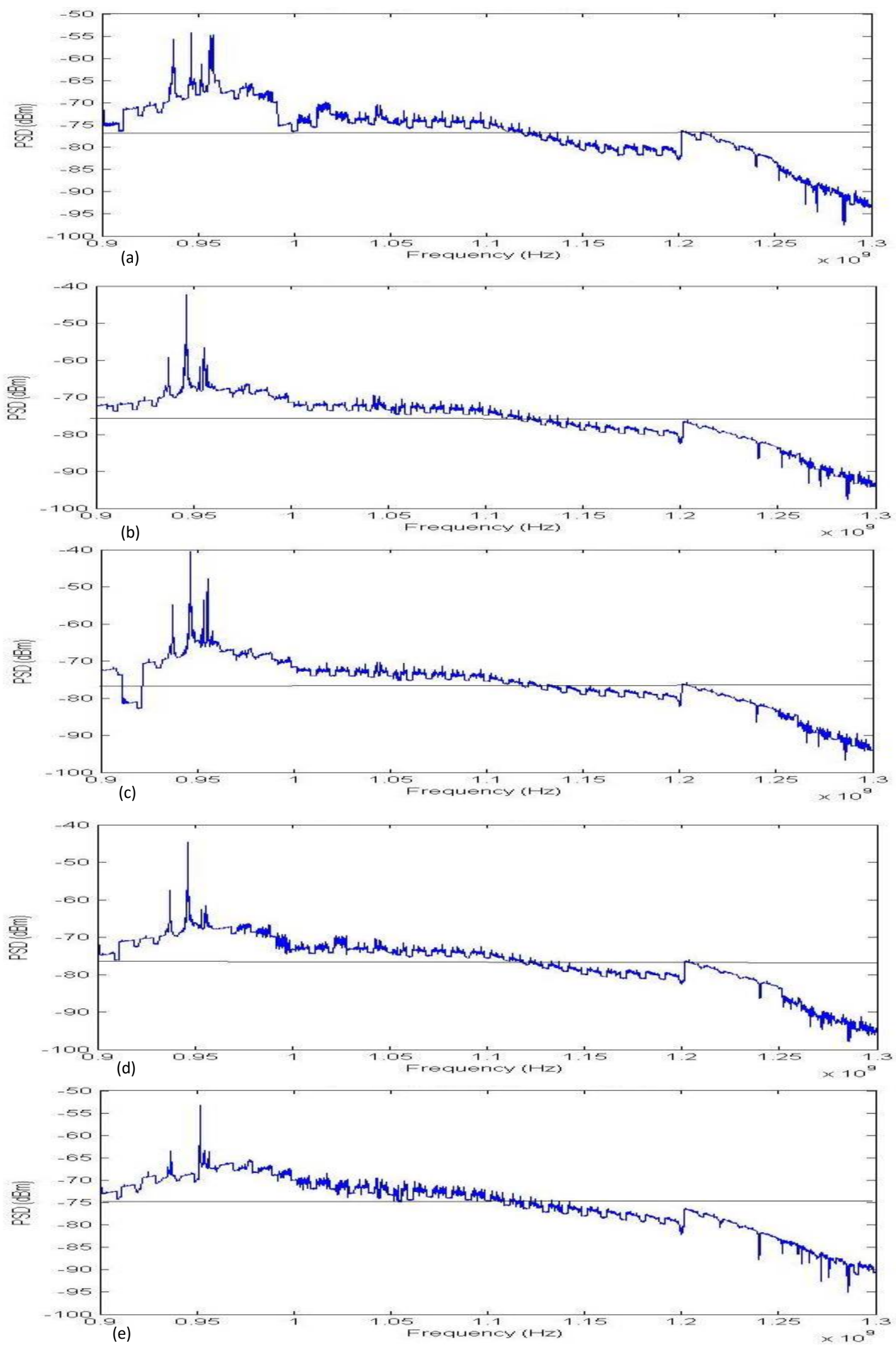

Figure 4. Typical frequency usage profile in (a) Abuja, (b) Lokoja, (c) Lafia, (d) Port-Harcourt and (e) Gusau respectively 
In addition, critical observation of Figures 4(a)-(e) shows three levels of spectral occupancy in all the studied areas and frequency bands considered. These three levels of spectrum occupancy according to [29] are black space, grey space and white space. The black space according to $[6,29,30]$ is frequency band that is occupied most of the time by high power signals while the grey space is frequency band that is scantily or partially occupied by low power signal. The white space on the other hand is the frequency band that in most of the time is not being occupied or used. Generally, these graphical occupancy usage profiles show clearly that spectrum usage vary in time, frequency and space in the studied locations and the whole country at large.

\subsection{Quantitative Duty Cycle Measurement Results}

The duty cycle is defined as the percentage of time a channel or frequency band is occupied over a given period. It is a term use in determining quantitatively how often a frequency band is occupied by the signal. Thus, in this sub-section, the numerical results of the actual spectrum occupancy in each respective location and frequency band are presented in Table 4 based on duty cycle determination using equation (2).

Table 4. Actual spectrum occupancy for each location and frequency band

\begin{tabular}{|c|c|c|c|c|c|c|}
\hline \multirow{2}{*}{$\begin{array}{c}\text { Application/ Frequency } \\
\text { Band }\end{array}$} & \multicolumn{5}{|c|}{ Spectrum Occupancy (\%) } & \multirow{2}{*}{$\begin{array}{c}\text { Average } \\
\text { Spectrum } \\
\text { Occupancy } \\
\text { per band (\%) }\end{array}$} \\
\hline & Abuja & $\begin{array}{c}\text { Port- } \\
\text { Harcourt }\end{array}$ & Lafia & Lokoja & Gusau & \\
\hline $\begin{array}{l}\text { Radio Band } \\
(80-150 \mathrm{MHz})\end{array}$ & 9.60 & 9.30 & 8.80 & 9.00 & 8.00 & 8.94 \\
\hline $\begin{array}{l}\text { TV and Land Mobile Band } \\
(150-400 \mathrm{MHz})\end{array}$ & 8.20 & 7.80 & 3.40 & 4.00 & 5.40 & 5.76 \\
\hline $\begin{array}{c}\text { TV Band } \\
(400-960 \mathrm{MHz})\end{array}$ & 9.20 & 8.80 & 5.40 & 5.00 & 6.40 & 6.96 \\
\hline $\begin{array}{c}\text { Trunk Radio } \\
(700-1000 \mathrm{MHz})\end{array}$ & 6.40 & 5.20 & 5.60 & 4.80 & 5.80 & 5.56 \\
\hline $\begin{array}{c}\text { GSM Band } \\
(900-1300 \mathrm{MHz})\end{array}$ & 11.20 & 11.60 & 8.80 & 10.00 & 7.40 & 9.80 \\
\hline $\begin{array}{l}\text { Rural Telecoms and GSM } \\
\quad(1300-1700 \mathrm{MHz})\end{array}$ & 8.50 & 8.00 & 4.90 & 4.30 & 5.70 & 6.28 \\
\hline $\begin{array}{l}\text { GSM, Oil Coy and Satellite } \\
\quad(1700-1900 \mathrm{MHz})\end{array}$ & 10.10 & 8.70 & 5.10 & 9.60 & 6.50 & 8.00 \\
\hline $\begin{array}{c}\text { 3G Band } \\
(1900-2200 \mathrm{MHz})\end{array}$ & 9.60 & 8.10 & 7.50 & 7.80 & 7.10 & 8.02 \\
\hline
\end{tabular}

The band-by-band spectrum occupancy statistics obtained in this study is presented in Table 4 . The results show the numerical variations in spectrum occupancy in time, space and frequency. The obtained results reveal spectral utilization range of $3.4 \%$ to $11.6 \%$, which is a little higher than the utilization range of $0.00 \%$ to $10.79 \%$ presented in [1] conducted in Ilorin, North-Central, Nigeria. Critical observation of Table 4 shows that the frequency band allocated for GSM 900 has the highest spectral occupancy across the five locations, which is similar to the result obtained in [18]. This implies that GSM $900(880-960 \mathrm{MHz})$ is one of the typical heavily utilized frequency bands across the world. Similarly, the frequency bands allocated for both radio broadcasting $(80-150 \mathrm{MHz})$ and digital cellular services (1900-2200 MHz) have moderate occupancy while low occupancy is observed in the frequency bands allocated for rural Telecoms. On the other hand, the frequency range of 1200- 
$1300 \mathrm{MHz}$ in Figures 4(a) - (e) is absolutely unused. Also, the result of this study shows that though some frequencies in some bands apparently appeared to be utilized, the duty cycle is actually extremely low. From these observations as well as the three level of spectrum occupancy graphically depicted in Figures 4(a) - (e), it is evident that some channels can be further studied for possibility of dynamic spectrum access (DSA), which is also known as opportunistic spectrum access (OSA), so as to enhance the radio spectrum utilization level in those areas and the whole nation at large.

\subsection{Selected Comparative Radio Spectrum Measurement Results}

In validating the result of this study, the average occupancy results for certain frequency bands were compared with results obtained from similar studies conducted in Nigeria and other parts of the world. The comparative study analysis is presented in Table 5.

Table 5. Comparative results of related works with present work

\begin{tabular}{|c|c|c|c|}
\hline Author(s) & Location & Frequency Range (MHz) & $\begin{array}{c}\text { Average } \\
\text { duty cycle } \\
(\%)\end{array}$ \\
\hline Present Work & $\begin{array}{l}\text { South-South, Nigeria } \\
\text { North-Central, Nigeria } \\
\text { North-West, Nigeria }\end{array}$ & $\begin{array}{c}880-960(\text { GSM 900) } \\
1710-1880(\text { GSM 1800) } \\
1885-2200(3 \mathrm{G}, \text { IMT-2000) }\end{array}$ & $\begin{array}{l}7.40 \\
6.50 \\
7.10\end{array}$ \\
\hline $\begin{array}{l}\text { Najashi et al. } \\
\text { (2015)[9] }\end{array}$ & North-Central, Nigeria & $\begin{array}{c}880-960 \text { (GSM 900) } \\
1710-1880(\text { GSM 1800) } \\
1885-2200(3 \mathrm{G}, \text { IMT-2000) }\end{array}$ & $\begin{array}{c}26.00 \\
25.56 \\
0.45\end{array}$ \\
\hline $\begin{array}{c}\text { Jayavalan et al. } \\
\text { (2014)[18] }\end{array}$ & Selangor, Malaysia & $\begin{array}{c}880-960(\text { GSM 900) } \\
1710-1880(\text { GSM 1800) } \\
1885-2200(3 G, \text { IMT-2000) }\end{array}$ & $\begin{array}{c}35.31 \\
9.59 \\
26.08\end{array}$ \\
\hline $\begin{array}{l}\text { Patil et al. } \\
\text { (2011)[31] }\end{array}$ & Mumbail, India & $\begin{array}{c}890-960(\text { GSM 900) } \\
1710-1880(\text { GSM 1800) } \\
1900-2400(3 \mathrm{G})\end{array}$ & $\begin{array}{c}37.20 \\
31.71 \\
3.15\end{array}$ \\
\hline & $\begin{array}{c}\text { Northern Suburb of } \\
\text { Brno, Czech Republic, } \\
\text { Europe }\end{array}$ & $\begin{array}{c}880-960 \text { (GSM 900) } \\
1710-1880 \text { (GSM 1800) } \\
1900-2025 \text { (UMTS) }\end{array}$ & $\begin{array}{l}38.00 \\
47.90 \\
44.40\end{array}$ \\
\hline $\begin{array}{l}\text { Valenta et al. } \\
\text { (2010)[15] }\end{array}$ & $\begin{array}{l}\text { Eastern Suburb of } \\
\text { Paris, (ESIEE Paris), } \\
\text { France, Europe }\end{array}$ & $\begin{array}{c}880-960 \text { (GSM 900) } \\
1710-1880 \text { (GSM 1800) } \\
1900-2025 \text { (UMTS) }\end{array}$ & $\begin{array}{l}22.00 \\
29.30 \\
15.60\end{array}$ \\
\hline & $\begin{array}{l}\text { City of Paris, Near } \\
\text { Place de la Nation, } \\
\text { Europe }\end{array}$ & $\begin{array}{c}\text { 880-960 (GSM 900) } \\
\text { 1710-1880 (GSM 1800) } \\
\text { 1900-2025 (UMTS) }\end{array}$ & $\begin{array}{c}2.10 \\
10.80 \\
11.10\end{array}$ \\
\hline $\begin{array}{l}\text { Islam et al. } \\
\text { (2008)[32] }\end{array}$ & Singapore & $\begin{array}{c}880-960 \text { (GSM 900) } \\
1710-1880(\text { GSM 1800) } \\
1885-2400(3 \mathrm{G}, \text { IMT-2000) }\end{array}$ & $\begin{array}{c}38.11 \\
19.82 \\
3.55\end{array}$ \\
\hline
\end{tabular}

Critical observation of the comparative analyses result shows that actual spectrum occupancy vary with both space or location and frequency worldwide. The result also shows relatively low radio spectrum usage in Nigeria compare to rest parts of the world. In addition, the comparative analyses result shows that unused $890-960 \mathrm{MHz}$ licensed spectrum range vary from $61.89 \%$ to $97.90 \%$ while the corresponding value for $1880-2400 \mathrm{MHz}$ vary from $55.60 \%$ to $99.50 \%$. These results show gross 
underutilization of radio spectrum worldwide. The result also shows that less than $8.00 \%$ of the licensed spectrum in Nigeria is in used in space, time and frequency. This low spectral occupancy rate suggests a hopeful future for dynamic spectrum access in Nigeria.

\section{CONCLUSION}

As today's society proper functionality depends on wireless or radio communication, which its primary enabler is radio spectrum, demand for and use of radio spectrum show no sign of reduction. However, the artificial radio spectrum scarcity by the current fixed radio spectrum allocation policy has made radio spectrum availability for emerging wireless systems and applications a great challenge. The policy has equally made it practically infeasible for small and medium size businesses from entering the wireless market as a result of the prohibitively expensive cost involved in obtaining spectrum license. This brings idea of flexibility access policy whereby unused portion of the licensed spectrum can be opportunistically used by secondary user(s). In using licensed spectrum in this opportunistic manner, availability of unused portion of the already licensed must be ascertained. This leads to series of radio spectrum occupancy studies conducted in different parts of the world. Similarly study conducted in multi-band and multi-location in Nigeria is presented in this paper. The study presented in this paper covers series of observations obtained from spectrum occupancy measurements conducted in 80-2200 MHz frequency range and associated analyses. The results obtained generally show that the actual radio spectrum usage profile in Nigeria is relatively low with an average occupancy less than $10.00 \%$ in the frequency range considered. In addition, the measurement results obtained revealed that significant amount of allocated spectrum in the frequency range considered are idle and grossly underutilized in space, time and frequency. Furthermore, the low spectral occupancy rate in the five major metropolises suggests a hopeful future for dynamic spectrum access in Nigeria so as to enhance the resource accessibility and sufficient supply for today's society. Thus, in order determine more objective spectrum occupancy level, further measurement campaigns targeted at rural areas will be conducted so as to identify appropriate frequency bands that are most suitable for dynamic or opportunistic spectrum access in the country.

\section{REFERENCES}

[1] Ayeni AA, Faruk N, Bello OW, Sowande OA., Onidare SO, Muhammad MY. Spectrum occupancy measurements and analysis in the 2.4-2.7 GHz band in urban and rural environments. International Journal of Future Computer and Communication 2016; 5: 142-147.

[2] López-Benítez M, Casadevall F. spectrum usage in cognitive radio networks: from field measurement to empirical models. IEICE Transactions on Communications 2014; E97-B: 242250.

[3] Mehdawi M, Riley N, Paulson K, Fanan A, Ammar M. spectrum occupancy survey in hull-uk for cognitive radio applications: Measurement and analysis. International Journal of Scientific \& Technology Research 2013; 2: 231-236.

[4] Xue J, Feng Z, Zhang P. spectrum occupancy measurements and analysis in Beijing. IERI Procedia 2013; 4: 295-302.

[5] Yin S, Chen D, Zhang Q, Liu M Li S. Mining spectrum usage data: A large-scale spectrum measurement study. IEEE Transactions on Mobile Computing 2012; 11: 1033-1046.

[6] Chiang RIC, Rowe GB, Sowerby KW. A quantitative analysis of spectral occupancy measurements for cognitive radio. In: IEEE 2007 Vehicular Technology Conference; 22-25 April 2007; Dublin, Ireland: pp. 3016-3020. 
[7] Popoola, JJ, van Olst R. Development and demonstration of graphical user interface spectrum sensing algorithm using some wireless systems in South Africa. Journal of Applied Science and Process Engineering 2015; 2: 44-63.

[8] Scutari G, Palomar, DP, Barbarossa S. Cognitive MIMO radio competitive optimality design based on subspace projections. IEEE Signal Processing Magazine 2008; 25: 46-59.

[9] Najashi BG, Almustaphar MD, Abdi AS, Ashurah SA. Spectrum occupancy measurement in Nigeria: Results and analysis. International Journal of Computer Science Issues 2015; 12: 156-165.

[10] Popoola JJ, Ogunlana OA, Ajie FO, Olakunle O, Akiogbe OA, Ani-Initi SM, Omtola SK. Dynamic spectrum access: A new paradigm of converting radio spectrum wastage to wealth. International Journal of Engineering Technologies 2016; 2: 124-131.

[11] Sanders FH. Broadband spectrum surveys in Denver, CO, San Diego, CA, and Los Angeles, CA: Methodology, analysis, and comparative results. In: 1998 IEEE Electromagnetic Compatibility Symposium; 2-4 August 1998; Seattle, WA, USA: pp. 988-993.

[12] Bedogni L, Felice MD, Malabocchia F, Bononi L. Indoor communication over TV gray spaces based on spectrum measurements. In: 2014 IEEE Wireless Communication and Networking Conference; 6-9 April 2014; Istanbul, Turkey: pp. 3218-3223.

[13] Höyhtyä M, Matinmikko M, Chen X, Hallio J, Auranen J, Ekman R., Röning J, Engelberg J, Kalliovaara J, Taher T, Riaz A, Roberson D. Measurements and analysis of spectrum occupancy in the 2.3-2.4 GHz band in Finland and Chicago; In: 2014 International Conference on Cognitive Radio Oriented Wireless Networks, 2-4 June 2014; Finland: pp. 96-101.

[14] McHenry MA, Tenhula PA, McCloskey D, Roberson DA, Hood S. Chicago spectrum occupancy measurements and analysis and a long-term studies proposal. In: 2006 International Workshop on Technology and Policy for Accessing Spectrum, 5 August 2006, Boston, USA. Online [Available]:http://citeseerx.ist.psu.edu/viewdoc/download?doi=10.1.1.518.5560\&rep=rep1\&type $=$ pdf. Accessed on July 16, 2017.

[15] Valenta V, Marsalek R, Baudoin G, Villegas M, Suarez M, Robert F. Survey on spectrum utilization in Europe: Measurements, analyses and observations; In: 2010 International ICST Conference on Cognitive Radio Oriented Wireless Networks and Communications, June 2010; Cannes, France: pp. 1-5. Online [Available]: https://hal.archives-ouvertes.fr/hal00492021/document. Accessed on December 11, 2016.

[16] López-Benítez M, Umbert MA, Casadevall F. Evaluation of spectrum occupancy in Spain for cognitive radio applications. In: 2009 IEEE Vehicular Technology Conference; 26-29 April 2009; Barcelona, Spain: pp. 1-5.

[17] Qaraqe KA, Celebi H, Gorcin A, El-Saigh A, Arslan H, Alouini MS. Empirical results for wideband multidimensional spectrum usage. In: 2009 IEEE International Personal, Indoor and Mobile Radio Communications Symposium; 13 - 16 September 2009; Tokyo, Japan: pp. 12621266.

[18] Jayavalan ., Mohama, H, Aripin NM, Ismail A, Ramli N, Yaacob A Ng MA. Measurements and analysis of spectrum occupancy in the cellular and TV bands. Lecture Notes on Software Engineering 2014; 2: 133-138. 
[19] Barnes SD, van Vuuren PAJ, Maharaj BT. Spectrum occupancy investigation: Measurements in South Africa. Measurement 2013; 46: 3098-3112.

[20] Ayugi G, Kisolo A, Ireeta TW. Telecommunication frequency band spectrum occupancy in Kampala Uganda. International Journal of Research in Engineering and Technology 2015; 4: 390-396.

[21] Matheson RJ. Strategies for spectrum usage measurements. In: 1988 IEEE International Symposium on Electromagnetic Compatibility; 2 - 4 Aug. 1988; Seattle, WA, USA: 235-241.

[22] Čabrić D, Mishra SM, Brodersen RW. Implementation issues in spectrum sensing for cognitive radios. In: 2004 Asilomar Conference on Signals, Systems and Computers; Pacific Grove, California, USA: pp. 772-776.

[23] Shankar NS, Cordeiro C, Challapali K. Spectrum agile radios: Utilization and sensing architectures. In: 2005 IEEE International Symposium on New Frontiers in Dynamic Spectrum Access Networks; Baltimore, MD, USA: pp. 160-169.

[24] Popoola JJ, and van Olst R. The performance evaluation of a spectrum sensing implementation using an automatic modulation classification detection method with a Universal Software Radio Peripheral. Expert Systems with Applications 2013; 40: 2165-2173.

[25] Hamdi K, Letaief KB. Cooperative communications for cognitive radio networks. In: 2007 Postgraduate Symposium, The Convergence of Telecommunications, Networks and Broadcasting, Liverpool John Moores University, pp. 1-5. Online [Available]: http://www.cms.livjm.ac.uk/pgnet2007/proceedungs/Papers/2007-087.pdf. Accessed on February 19, 2009.

[26] López-Benítez M, Casadevall F. An overview of Spectrum occupancy models for cognitive radio networks. In: 2011 International Federation for Information Processing, LNCS 6827, Valencia, Spain, pp. 32-41. Online [Available]: https://link.springer.com/content/pdf/10.1007\%2F978-3642-23041-7_4.pdf. Accesssed on July 20, 2017.

[27] Chen D, Yang J, Wu J, Tang H, Huang M. Spectrum occupancy analysis based on radio monitoring network. In: 2012 IEEE International Conference on Communications in China: Wireless Networking and Applications; 15-17 August 2012; Beijing, China: pp. 739-744.

[28] Popoola JJ, Obafemi AC. Technical Evaluation of Level of Radiation Exposure from GSM Base Stations to the Public in Nigeria. Journal of Engineering and Technology 2016; 7: 60-74.

[29] Haykin S. Cognitive radio: Brain-empowered wireless communications. IEEE Journal on Selected Areas in Communications 2005; 23: 201-220.

[30] Renk T, Kloeck C, Jondral FK. A cognitive approach to the detection of spectrum holes in wireless networks. In: 2007 IEEE Consumer Communications and Networking Conference; 1113 January 2007; Las Vegas, NV: pp. 1118-1122.

[31] Patil K, Skouby K, Chandra A, Prasad R. Spectrum occupancy statistics in the context of cognitive radio. In 2011 International Symposium on Wireless Personal Multimedia Communication; 3-7 October 2011; Breast, France: pp. 1-5.

[32] Islam MD, Koh CH, Oh SW, Qing X, Lai YY, Wang C, Liang Y-C, Toh BE, Chin F, Tan GL, Toh William. Spectrum survey in Singapore: Occupancy measurements and Analyses. In 2008 IEEE International Conference on Cognitive Radio Oriented Wireless Networks and Communications; 15-17 May 2008; Singapore, Singapore: pp. 1-7. 